Journal of Applied Pharmaceutical Science Vol. 6 (12), pp. 190-191, December, 2016

Available online at http://www.japsonline.com

DOI: $10.7324 / \mathrm{JAPS} .2016 .601227$

ISSN 2231-3354 (cc) BY-NC-SA

\title{
Cefoperazone: A Rare Cause of Thrombocytopenia
}

\author{
A. Avinash, Sushil Kiran Kunder, Bharti Chogtu Magazine* , K. L. Bairy, Shalini Adiga \\ Department of Pharmacology, Kasturba Medical College, Manipal University, Manipal, India.
}

\author{
ARTICLE INFO \\ Article history: \\ Received on: 27/07/2016 \\ Revised on: 24/08/2016 \\ Accepted on: 30/09/2016 \\ Available online: $28 / 12 / 2016$ \\ Key words: \\ Platelet; Beta-Lactam; \\ Cephalosporins; Antibiotic; \\ Bleeding; \\ Hypoprothrombinemia.
}

\begin{abstract}
Beta lactam antibiotics are one of the most commonly prescribed antibiotic drug classes in medical practice. Cephalosporins differ from other beta lactam antibiotics in both their structure and spectrum of action. Beta lactam antibiotics, in general, may cause platelet deficiency owing to their interference with normal platelet function. Cefoperazone, belonging to the group of $3^{\text {rd }}$ generation cephalosporins, has been reported to cause hypoprothrombinemia and hence, bleeding manifestations. However, it is not known to alter platelet function and count at the routinely used therapeutic doses. This case report highlights a rare case of cefoperazoneinduced thrombocytopenia.
\end{abstract}

\section{INTRODUCTION}

Cephalosporins are beta-lactam antibiotics. Like penicillins, cephalosporins also inhibit bacterial cell wall synthesis. Cefoperazone is a third generation cephalosporin which has additional activity against Pseudomonas. Unlike other third generation cephalosporins, cefoperazone is excreted in bile. Common adverse effects of cefoperazone are diarrhoea (as they are excreted in bile), hypoprothrombinaemia, disulfiram-like reaction, etc. Hypoprothrombinaemia and disulfiram-like reaction are attributed to the presence of methylthiotetrazole group (Petri, 2011). The normal platelet count is 150,000 to 450,000 cells/cu.mm. When the count falls below the lower limit of this range, it is called thrombocytopenia. Thrombocytopenia can be due to sequestration owing to an enlarged spleen, increased platelet destruction, or decreased platelet production. Many drugs are known to cause thrombocytopenia like heparin,

\footnotetext{
* Corresponding Author

E-mail: bharti.magazine @ manipal.edu
}

linezolid, tamoxifen, etc. (Konkle, 2012; Pathak et al., 2016). The following is a case report of cefoperazone-induced thrombocytopenia that was collected as a part of ADR monitoring in Kasturba Medical College, Manipal, India.

\section{CASE REPORT}

A 46-year old male patient was admitted in the medical ward with complaints of burning micturition and high grade fever $\left(101^{\circ} \mathrm{F}\right)$ associated with chills and rigors on 13/05/2015. Vital signs were normal and systemic examination did not reveal any abnormality. A diagnosis of left-sided pyelonephritis was made after a KUB ultrasound screening was done on the day of admission. The patient had been operated under spinal anaesthesia and a double J stent was placed in his left kidney on 30/04/2015.

The patient was started on intravenous cefoperazone $2 \mathrm{~g}$ twice daily and sulbactam 500mg twice daily on 13/05/2015 (Day 1 ). His platelet count was $1,81,000$ cells/cu.mm on the day of admission. On 16/05/2015, the patient developed episodes of haematuria. So, his platelet levels were checked again. 
Platelet count was found to be low ("Low" according to the automated analyzer). The count was repeated the next day. On day 5 , the platelet count was 10,000 cells/cu.mm. Following this, the antibiotic was stopped. Also, four units of platelets $(50 \mathrm{ml}$ each) were transfused on the early morning of day 6 . The platelet count improved to 25,000 cells/cu.mm, 29,000 cells/cu.mm and 83,000 cells/cu.mm on the subsequent days.

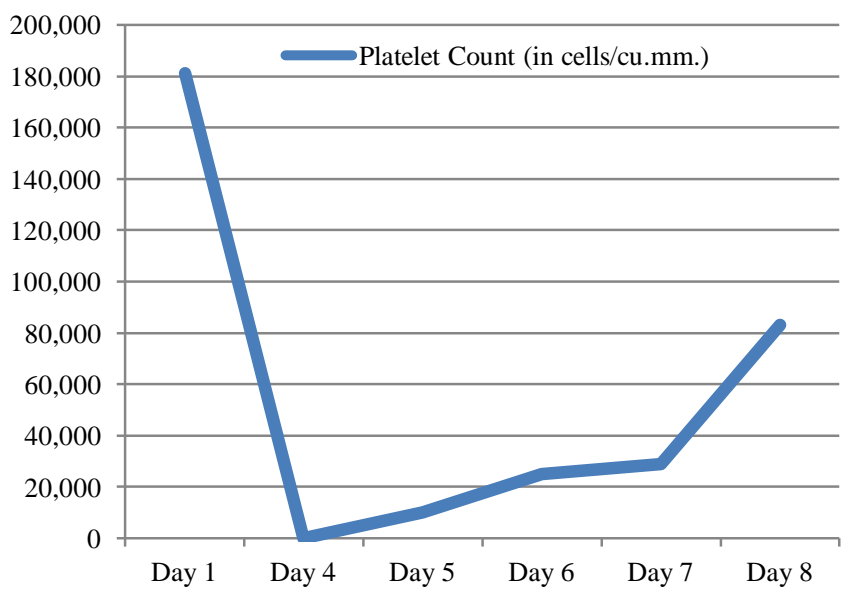

Fig. 1: Platelet Count (in cells/cu.mm.)

The patient is a known case of type 2 diabetes mellitus for the past 2 years, and is on regular treatment with oral glimepiride $1 \mathrm{mg}$ once daily. During his stay in the hospital, he was also being given subcutaneous human insulin for optimal control of blood sugar. He was not on any other chronic medication. For pain management, oral paracetamol $650 \mathrm{mg}$ thrice daily was being given during his stay in the hospital.

Rechallenge with cefoperazone was not done for ethical reasons, as thrombocytopenia is a potentially life-threatening condition. This ADR falls under the "PROBABLE" category, based on both the WHO causality scale and the Naranjo's algorithm.

\section{DISCUSSION}

Cephalosporins are broad spectrum antibiotics that belong to the class of beta-Lactams. They are broadly divided into five generations, with cefoperazone falling under third generation, alongside ceftriaxone, cefixime, cefotaxime, etc. Cefoperazone has additional activity against Pseudomas, and hence commonly used in respiratory and urinary tract infections (Petri, 2011).

Cefoperazone, like all other beta lactam antibiotics, acts by inhibiting the bacterial cell wall synthesis. It does so by inhibiting the transpeptidation reaction which in turn inhibits peptidoglycan synthesis, leading to improper cell wall formation (Tripathi, 2013).

Cefoperazone is not known to alter platelet function but it may cause bleeding manifestations by causing hypoprothrombinemia (due to the methyl-tetrazol-thiomethyl group present in its structure) (Tripathi, 2013). However, being a beta lactam antibiotic, it may interfere with platelet function by: a. Preventing the binding of agonists (ADP, collagen) to the platelet membrane

b. Preventing the influx of calcium $\left(\mathrm{Ca}^{2+}\right)$ ions into the platelet cell

Normal functioning of platelet cells requires physiological ligands like ADP and collagen to bind to the cell membrane, thereby helping in platelet aggregation (Cazzola et al., 1993). Also, influx of $\mathrm{Ca}^{2+}$ ions is essential for activation of platelet cells. By interfering with the above mentioned mechanisms, cefoperazone may cause loss of platelet activation and aggregation, leading to platelet dysfunction which presents clinically as bleeding manifestations (Schulz et al., 2010). However, the cause for reduction in platelet count is unknown. It may be due to immunemediated destruction of platelet cells as seen in several other causes of drug-induced thrombocytopenia, although evidence is lacking for this mechanism. In early clinical trials with cefoperazone, it was observed that the drug actually caused thrombocytosis in about $30 \%$ of the subjects (Parry, 1984).

To conclude, as encountered with other beta lactam antibiotics, cefoperazone may also cause thrombocytopenia. Hence, it is imperative to monitor platelet counts in patients on this cephalosporin antibiotic. Larger controlled studies (with cefoperazone and other beta lactams) may be required to assess the actual incidence of this uncommon adverse effect.

\section{Financial support and sponsorship: Nil.}

Conflict of Interests: There are no conflicts of interest.

\section{REFERENCES}

Cazzola M, Matera MG, Santangelo G, Lampa E, Angrisani M, Loffreda A et al. Effects of some cephalosporins and teicoplanin on platelet aggregation. International Journal of Clinical Pharmacology Research. 1993; 13(2): 69-73.

Konkle B. Disorders of platelets and vessel wall. Longo DL, Kasper DL, Jameson JL, Fauci AS, Hauser SL, Loscalzo J. Harrison's Principles of Internal Medicine. McGraw-Hill Inc. $18^{\text {th }}$ edition. 2012: 9657.

Parry MF. Toxic and adverse reactions encountered with new beta-Lactam antibiotics. Bull N Y Acad Med. 1984. 60 (4): 358-68.

Pathak A, Kunder SK, Avinash A, Patil N, Rao NK. A Rare Case of Tamoxifen-Induced Thrombocytopenia. J App Pharm Sci 2016;6(1):156-7.

Petri WA. 2011. Penicillin, Cephalosporins, and other betaLactam Antibiotics. Brunton L, Chabner B, Knollman B. Goodman and Gilman's the Pharmacological Basis of Therapeutics. McGraw-Hill Inc. $12^{\text {th }}$ edition. pp. 1493-9.

Schulz C, von Beckerath O, Okrojek R, von Beckerath $\mathrm{N}$, Massberg S. Platelet dysfunction and inhibition of multiple electrode platelet aggregometry caused by penicillin. Thrombosis Journal 2010 , $8: 13$.

Tripathi KD. 2013. Beta-lactam antibiotics. Essentials of Medical Pharmacology. Jaypee Publishers. $7^{\text {th }}$ edition.pp. 728.

How to cite this article:

Avinash A, Kunder SK, Magazine BC, Bairy KL, Adiga S, Patil N. Cefoperazone: A Rare Cause of Thrombocytopenia. J App Pharm Sci, 2016; 6 (12): 190-191. 